\title{
COVID-19: contextualizando a pandemia em visita a literatura
}

\section{COVID-19: contextualizing the pandemic in a literature tour}

DOI: $10.46919 / \operatorname{archv} 2 \mathrm{n} 3-033$

Recebimento dos originais: 01/01/2021

Aceitação para publicação: 31/03/2021

Eidimara Ferreira

Esteticista. Docente. Mestre em Envelhecimento Humano.

Universidade de Passo Fundo- UPF /Av. Brasil Leste, 285 - São José, Passo Fundo - RS, 99052-900

E-mail: eidimara@upf.br

\section{Thais Caroline Fin}

Médica. Docente. Mestre em Envelhecimento Humano.

Universidade de Passo Fundo- UPF/Av. Brasil Leste, 285 - São José, Passo Fundo - RS, 99052-900

E-mail: thaisfin@upf.br

Marilene Rodrigues Portella

Enfermeira. Docente.Doutora em Enfermagem.

Universidade de Passo Fundo- UPF/Av. Brasil Leste, 285 - São José, Passo Fundo - RS, 99052-900

E-mail: portella@upf.br

\section{Jéssica Lusa Favretto}

Esteticista e Cosmetóloga.

Universidade de Passo Fundo (UPF)

Comunidade São Domingos - Interior de Tapejara - Rio Grande do Sul

E-mail: jessikalf@hotmail.com

\section{RESUMO}

A Organização Mundial da Saúde, em 11 de março de 2020, anunciou a pandemia da doença de coronavírus 2019 (COVID-19) e desde então, o número de infectados vêm aumentando, ocasionando altas taxas de morbimortalidade em todo o mundo. Essa doença tornou-se uma emergência de saúde pública de interesse internacional, uma ameaça à saúde global com um número continuamente crescente de casos confirmados. Este capítulo tem por objetivo apresentar aspectos relacionados ao coronavírus, as variantes, a epidemiologia da doença e as medidas preventivas. Trata-se de uma revisão bibliográfica, realizada por meio eletrônico nas bases de dados Biblioteca Virtual em Saúde (BVS), Pubcovid19 e Medical Literature Analysis and Retrievel System Online (MEDLINE). Conclui-se que a pandemia COVID-19 é a principal crise de saúde global da contemporaneidade porém, é muito mais que uma crise de saúde, é também uma crise socioeconômica sem precedentes, com efeitos sociais, econômicos e políticos, repercussões de difícil dimensionamento. A importância das medidas de prevenção, assim como estar atento aos sintomas e as formas de transmissão é imprescindível, pois abrange o indivíduo e também as suas relações interpessoais, evidenciando-se a importância da empatia. Ainda há um longo caminho até que se tenha total controle da mesma, através de um tratamento efetivo ou até mesmo evitando a Covid-19 com a vacinação.

Palavras chave: Coronavírus. Epidemiologia. Pandemia. Medidas preventivas. 


\begin{abstract}
The World Health Organization, on March 11, 2020, announced the 2019 coronavirus disease pandemic (COVID-19) and since then, the number of infected people have been increasing, causing high morbidity and mortality rates worldwide. This disease has become a public health emergency of international concern, a threat to global health with a continuously increasing number of confirmed cases. This chapter aims to present aspects related to coronavirus, the variants, the epidemiology of the disease, and preventive measures. This is a literature review, carried out electronically in the databases Virtual Health Library (VHL), Pubcovid19, and Medical Literature Analysis and Retrieval System Online (MEDLINE). We conclude that the COVID-19 pandemic is the main global health crisis of our time, but it is much more than a health crisis; it is also an unprecedented socioeconomic crisis, with social, economic and political effects, repercussions that are difficult to measure. The importance of prevention measures, as well as being aware of the symptoms and the ways of transmission is essential, because it covers the individual and also his interpersonal relationships, highlighting the importance of empathy. There is still a long way to go to have total control of it, through effective treatment or even by avoiding Covid-19 with vaccination.
\end{abstract}

Key words: Coronavirus. Epidemiology. Pandemic. Preventive Measures.

\title{
1 INTRODUÇÃO
}

Em 31 de dezembro de 2019, a China foi o primeiro país a notificar a Organização Mundial da Saúde (OMS) sobre a ocorrência de uma doença respiratória, a síndrome respiratória aguda grave causada por um novo tipo de coronavírus 2 (SARS-CoV-2), na cidade de Wuhan, província de Hubei da China (OMS 2020a). Logo tornou-se uma emergência de saúde pública de interesse internacional, uma ameaça à saúde global com um número continuamente crescente de casos confirmados, em 11 de março a OMS anunciou a pandemia da COVID-19 (KUMAR et al., 2021). Desde então, os casos da COVID-19 vêm aumentando, levando a altas taxas de morbimortalidade em todo o mundo.

Nas últimas décadas, a pandemia da COVID-19 é o terceiro grande surto, o primeiro foi a síndrome respiratória aguda grave (SARS) em 2002-2003 e o segundo, a síndrome respiratória do Oriente Médio (MERS) em 2012 (ADHIKARI et al., 2020). O aumento na frequência e no alcance das epidemias de doenças infecciosas pode ser atribuída a maior mobilidade humana, na atualidade. Quando o surto não é contido, ele se espalha por uma grande população e atinge toda uma região ou comunidade, causando uma epidemia. As pessoas vivem em um mundo interconectado e globalizado, podem ir de um local a outro ponto do planeta em apenas um ou dois dias, levando consigo vírus, bactérias, doenças que adquirem, e, com potencial de causar a disseminação de doenças infecciosas emergentes e reemergentes. À medida que pessoas infectadas ou objetos contaminados com material infeccioso se espalham pelo mundo, uma epidemia se transforma em uma pandemia. (RODRIGUEZ-MORALES et al., 2020), por isso a pandemia da COVID-19 comprometeu a segurança da saúde global. Até o início do mês de junho de 2021 houveram 173.674.509 casos confirmados de COVID-19, incluindo 3.744.408 mortes, notificados à OMS (WHO, 2021) dos quais $40 \%$ dos casos e $47 \%$ das mortes ocorreram na região das Américas (OPAS/OMS, 2021c). 
Este capítulo tem por objetivo apresentar aspectos relacionados ao coronavírus, as variantes, a epidemiologia da doença e as medidas preventivas. Trata-se de uma revisão bibliográfica, realizada por meio eletrônico nas bases de dados Biblioteca Virtual em Saúde (BVS), Pubcovid19 e Medical Literature Analysis and Retrievel System Online (MEDLINE).

\section{SOBRE O VÍRUS E SEU HOSPEDEIRO}

A maioria das pandemias encontradas pela humanidade nos últimos tempos são zoonoses que geralmente são transmitidas aos humanos por meio do contato direto com fluidos corporais de animais ou por meio de vetores que carregam patógenos zoonóticos (CUI; LI; SHI, 2019).

Acredita-se que a SARS, em 2002-2003, e a MERS, que continuou a se espalhar na península arábica desde 2012, tenham sido transmitidas aos humanos por meio de gatos civetas e camelos dromedários, respectivamente (SHE et al., 2020). As zoonoses se amplificam nos corpos dos animais (reservatórios dos animais) sem serem fatais para o hospedeiro. Os morcegos, por exemplo, servem como reservatórios perfeitos, pois têm interferons adequados para se proteger da doença real e, ao mesmo tempo, amplificar a carga do patógeno (CUI; LI; SHI, 2019).

Os morcegos parecem ser os principais hospedeiros reservatórios de muitos coronavírus, como SARS-CoV, MERS-CoV e SARS-CoV-2, são uma ordem muito diversa de mamíferos (Ordem Chiroptera), com aproximadamente 1240 espécies (CUI; LI; SHI, 2019). Uma em cada quatro espécies de mamíferos na terra é um morcego, com exceção das regiões polares e algumas ilhas oceânicas, eles podem ser encontrados em todos os continentes, o que significa que há uma boa chance de que um vírus venha de um morcego (WANG; ANDERSON, 2019).

Acredita-se que a pandemia COVID19 causada pelo vírus SARS-CoV-2, tenha surgido de um animal hospedeiro cujo genoma compartilha $96 \%$ de similaridade com o betacoronavírus isolado de um morcego em 2013 (RaTG13). A sequência ao receptor (RBM) do SARS-CoV-2, que é decisiva para a infecção do hospedeiro, também compartilha uma alta similaridade de sequência com o betacoronavírus isolado de um pangolim malaio. Portanto, julga-se que o SARS-CoV-2 se originou em morcegos e passou por múltiplos eventos de recombinação ao migrar para outros mamíferos (CUI; LI; SHI, 2019; WANG; ANDERSON, 2019; WONG et al., 2020).

Os coronavírus contêm um RNA positivo, têm um grande genoma e possuem engenharia sofisticada para dominar as células hospedeiras. Eles são conhecidos por cruzar as barreiras das espécies, infectar humanos e sequestrar as células hospedeiras para se e replicar e se espalhar. Dos coronavírus que anteriormente eram conhecidos por infectar humanos sabia-se que causavam resfriados comuns, doenças respiratórias superiores e doenças intestinais. Destes, os betacoronavírus como o SARS e o coronavírus MERS causam infecções graves e frequentemente fatais do trato respiratório inferior (CUI; LI; SHI, 2019). 
O RNA viral isolado de pacientes COVID-19 em Wuhan foi sequenciado e um betacoronavírus com características genômicas únicas, incluindo um par de novas proteínas curtas putativas que potencializam a replicação e transmissão das proteínas virais foi identificado (CHAN et al, 2020). Múltiplos estudos de sequenciação genômica independentes conduzidos no RNA viral SARS-CoV-2 isolado de vários pacientes COVID-19 demonstraram uma relação filogenética com um coronavírus de morcego e um coronavírus de pangolin (CHAN et al, 2020).

\section{SOBRE ALGUMAS VARIANTES IDENTIFICADAS}

O surgimento de mutações é um evento natural e esperado dentro do processo evolutivo dos vírus. Desde a caracterização genômica inicial do SARS-CoV-2, este vírus se dividiu em diferentes grupos genéticos, por conseguinte, surgiram as variantes. Variantes é a denominação que se dá as mutações adicionais que geram diferenças dentro de cada grupo genético atribuída aos diversos processos de microevolução e pressões de seleção (OPAS/OMS, 2021a).

Desde a identificação inicial do SARS-CoV-2 até o momento já foram registradas mais de 400 mil sequências genômicas completas no mundo todo. Em 14 de dezembro de 2020, o Reino Unido notificou a OMS sobre uma variante denominada como SARS-CoV-2 VOC 202012/01. Essa variante contém 23 substituições de nucleotídeos e não estava filogeneticamente relacionada ao vírus SARS-CoV-2 que circulava no Reino Unido quando ela foi detectada. As autoridades sanitárias atribuem a esta variante o aumento substancial de casos, bem como, a transmissibilidade em comparação com outras variantes e reconhecem como a variante dominante em grande parte do Reino Unido (OPAS/OMS, 2021). Até o mês de janeiro de 202, além do Reino Unido, 62 países e territórios das seis regiões da OMS notificaram casos importados ou transmissão comunitária de VOC 202012/01 (WHO, 2021).

Uma nova variante do SARS-CoV-2 foi anunciada em dezembro de 2020, na África do que se espalhou rapidamente em três províncias sul-africanas. A África do Sul denominou essa variante de 501Y.V2, devido a uma mutação N501Y. Até janeiro de 2021, além da África do Sul, mais 30 países de cinco das seis regiões da OMS notificaram casos da variante 501Y.V2 (OPAS/OMS, 2021b).

A notificação de novas variantes, além das supracitadas, já foram registradas pelo Brasil, Estados Unidos e o Japão. No Brasil, em março de 2020, a linhagem B.1.1.28 foi descrita pela primeira vez, pelo Instituto Adolfo Lutz, em um paciente de 22 anos. Variante esta, também notificada pelo Japão a OMS, em janeiro de 2021, detectada em quatro brasileiros que chegaram ao país (FARIA; MORALES; CANDIDO, 2021).

Em Manaus, em dezembro de 2020, foram detectados casos das variantes P.1 e P.2, da linhagem B.1.1.28. Até janeiro de 2021, oito países e territórios em três das seis regiões da OMS notificaram casos da variante P.1, linhagem B.1.1.28 (OPAS/OMS, 2021b). O número global de países e territórios, com os 
casos de notificação de variantes, vem aumentando, bem como outras mutações de interesse para a saúde pública na Região das Américas nas Américas. No quadro 1 apresentamos um resumo sobre os números de casos relatados de variantes de preocupação (VOC) com a evolução atualizada até maio de 2021.

Quadro 1 - Resumo dos países/territórios que notificaram casos de variantes de preocupação (VOC) em 17 de maio de 2021.

\begin{tabular}{|c|c|c|c|c|}
\hline \multirow[t]{2}{*}{ Resumo } & \multicolumn{4}{|c|}{ Nome da variante } \\
\hline & B.1.1.7 & B.1.351 & P.1 & B. 1.617 \\
\hline $\begin{array}{l}\text { Número de países/territórios a nível global } \\
\text { que notificaram casos }\end{array}$ & 142 & 97 & 56 & 44 \\
\hline $\begin{array}{l}\text { Número de países/territórios nas Américas } \\
\text { que notificaram casos }\end{array}$ & 36 & 17 & 21 & 8 \\
\hline
\end{tabular}

Fonte: OPAS/OMS. Actualización Epidemiológica Enfermedad por coronavirus (COVID-19)18 de mayo de 2021, p.10

A OMS insiste para que cada país realize a vigilância genômica no âmbito da Rede Regional de Vigilância Genômica de COVID-19, estimulando os estados membros a participar dessa Rede e a realizar o sequenciamento, pois a detectar as variantes é de interesse em saúde pública. A OMS recomenda monitorar as mudanças repentinas e significativas de incidência de casos, os quais possam atingir um percentual de $50 \%$ em um período de 2-4 semanas, em situações em que a população acatou as medidas preventivas de saúde pública e de distanciamento social (OPAS/OMS, 2021b).

\section{TRANSMISSÃO E MANIFESTAÇÕES CLÍNICAS DA COVID-19}

A literatura atual aponta que o SARS-CoV-2 pode se espalhar por meio do contato direto, indireto (através de superfícies ou objetos contaminados) ou próximo (na faixa de um metro) com pessoas infectadas através de secreções como saliva ou gotículas respiratórias, expelidas durante a fala, por meio da tosse ou espirros, mas há que se considerar também os fatores ambientais (KUMAR et al., 2021), conforme ilustra a figura 1. 
Figura 1 - Diagrama representativos das vias de transmissão

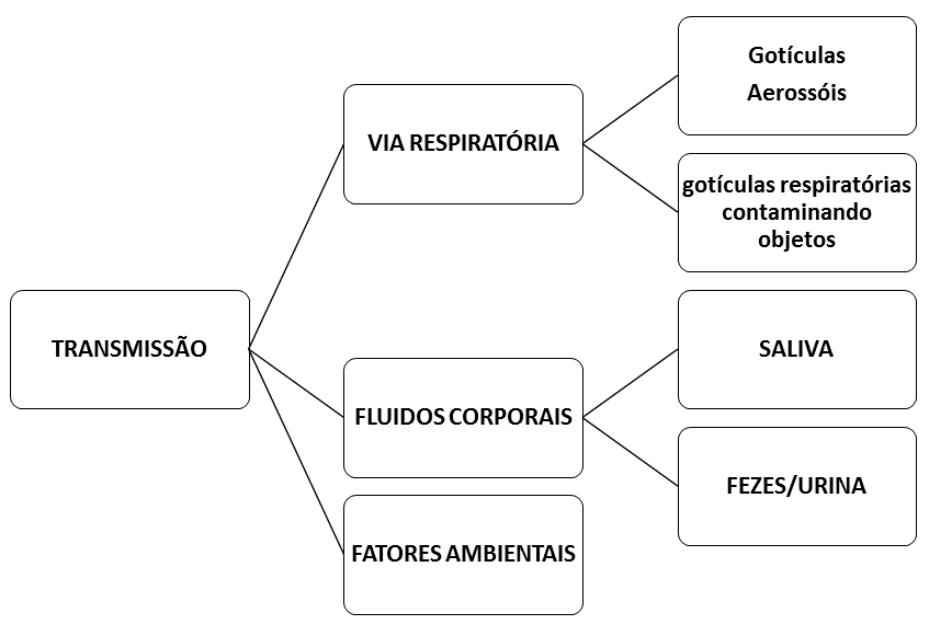

Fonte: elaborado pelas autoras

Espirros frequentes e tosse seca exibida pelo paciente com COVID-19 geram plumas virais de milhares de gotas por centímetro cúbico. As pessoas que estão em contato próximo (a menos de 1 metro) com uma pessoa infectada podem pegar se infectar quando essas gotículas infecciosas entrarem na sua boca, nariz ou olhos (SALIAN et al., 2021).

O estudo Yang et al. (2007), identificou que espirros e tosse seca geram tamanhos de gotículas que variam entre 0,6 e $100 \mu \mathrm{m}$, e o número de gotículas aumenta proporcionalmente com a taxa de tosse, isso ilustra o potencial de transmissão dos pacientes com COVID-19. Pacientes pré ou assintomáticos também podem gerar e emitir grandes quantidades de gotículas, menores que $1 \mu \mathrm{m}$, por meio da respiração e da fala (ASADI et al., 2020).

O estudo de Van Doremalen et al. (2020), informa que os aerossóis SARS-CoV-2 permanecem circulando no ar por um período de pelo menos $3 \mathrm{~h}$ com meia-vida de cerca de $1 \mathrm{~h}$, tempo este com potencial de contágio para infectar o indivíduo. Estudo aponta que o RNA viral SARS-CoV-2 foi detectado no trato respiratório superior em pacientes sintomáticos e assintomáticos, destacando o papel do epitélio nasal como reservatório viral e na disseminação do vírus pela mucosa respiratória (SUNGNAK et al., 2020), entretanto, a maioria das gotículas ou aerossóis com SARS-CoV-2 podem atingir às partes mais profundas do pulmão, uma vez que são um dos primeiros órgãos afetados na COVID-19.

O estudo Ling et al. (2020) confirma que o vírus pode estar presente nas fezes humanas e há relatos de que o RNA viral pode ser persistentemente eliminado nas fezes por um máximo de 33 dias após o paciente ter testado negativo para RNA viral respiratório (Wu et al., 2020). Embora não esteja claro se o SARS-CoV-2 pode ser transmitido pela via fecal-oral (Xu et al., 2020), a eliminação viral do sistema digestivo pode durar mais do que a eliminação do trato respiratório e como tal, a transmissão fecal-oral pode ser uma via importante, o que exige medidas sanitárias e conscientização das pessoas a higienização rigorosa e tratamento dos efluentes. Embora ainda não haja nenhuma evidência robusta de que o 
coronavírus seja transmitido diretamente pela via fecal-oral, o aumento da carga viral no ambiente pode aumentar a exposição humana potencial.

Alguns fatores ambientais são descritos como potenciais influências na infecção do SARS-CoV-2, quais sejam; níveis de concentração de poluentes no ar, condições meteorológicas, condições atmosféricas e topografia que afetam a dispersão de poluentes, densidade populacional, características culturais, entre outros (KUMAR et al., 2020; DATTAS et al., 2020). O estudo realizado em regiões italianas de altos índices de poluição aponta correlação positiva entre altas concentrações de poluentes atmosféricos e fatalidades da COVID-19, as regiões da Lombardia e Emilia Romagna da Itália, que testemunharam alta taxa morbimortalidade decorrente da COVID-19, estão entre as áreas mais poluídas da Europa (CONTICINI et al. 2020). Os autores ainda destacam que outros fatores que contribuem para infecções interespécies são o desmatamento e os ecossistemas alterados (que resultam na privação viral de seus hospedeiros naturais, fornecendo, portanto, a base para a infecção humana), comércio ilegal de animais selvagens, criação intensiva de animais domésticos e distribuição em grande escala de alimentos não controlados de origem animal. A atual pandemia COVID-19 destaca o quão vulneráveis somos ao risco de novos vírus serem intensificados por fatores ambientais.

As manifestações clínicas de COVID-19 não são específicas, mas semelhantes a muitas doenças virais. Após um período de incubação de cerca de 4 a 14 dias, a maioria dos indivíduos desenvolve sintomas que podem variar de leve a muito grave e até doença fulminante (GUAN et al., 2020). As manifestações mais comuns são tosse, febre, fadiga, anorexia e dores musculares (mialgias), a perda do olfato (anosmia) e a perda do paladar (disgeusia) podem ser frequentemente observadas e se acredita que sejam características, mas não exclusivas, do COVID-19 (GIACOMELLI et al. 2020). Dor de garganta, dor de cabeça e coriza (rinorreia) também são relatados. Sintomas gastrointestinais, como náusea e diarreia, e dor abdominal associada podem preceder os sintomas respiratórios em até $10 \%$ dos pacientes. Indivíduos assintomáticos podem testar positivo para COVID-19 (GUAN et al., 2020). Há registro na literatura que a maioria dos indivíduos apresentará doença leve a moderada, entretanto cerca de $30 \%$ dos pacientes podem desenvolver falta de ar (dispneia) por volta do $5^{\circ}$ dia após o início da doença. A piora do quadro clínico na segunda semana da doença é típico em pacientes com uma forma mais grave da doença. Esses pacientes geralmente requerem hospitalização no dia 7 ou 8 e manifestam baixo nível de oxigênio no sangue (hipoxemia), bem como pneumonia bilateral e insuficiência respiratória grave. A elevação das enzimas hepáticas e da creatinina também são comuns (GIACOMELLI et al. 2020; GUAN et al., 2020) 


\section{MEDIDAS PREVENTIVAS}

Para a prevenção contra o Coronavírus, existem algumas medidas básicas a serem adotadas, entre elas está à higienização das mãos frequentemente com água e sabão, por pelo menos 20 segundos, ou o uso de álcool em gel (70\%) para desinfecção. A recomendação é que a higiene seja completa, desde a parte inferior das pontas das unhas até a região do pulso. Deve-se também evitar o toque em olhos, nariz e boca quando as mãos não estiverem devidamente higienizadas. É importante realizar a higienização em superfícies e objetos que são tocados frequentemente, além de manter o ambiente sempre limpo e ventilado (WHO, 2020; BRASIL, 2020).

De forma a prevenir o contágio pelo Coronavírus, outra medida recomendada é o distanciamento social, evitando assim aglomerações, manter um distanciamento, de no mínimo um metro de distância, principalmente de pessoas que estejam próximas com sintomas de tosses ou espirros, para evitar que gotículas que possam conter o vírus sejam inaladas. O uso de máscaras juntamente com as práticas de higiene é outra forma que ajuda a prevenir a disseminação do vírus no ar (SANTOS, 2020; WHO, 2020).

O isolamento domiciliar é uma forma de prevenir os riscos de transmitir infecções respiratórias. A pessoa que apresentar caso suspeito da COVID-19 é submetida a ficar em casa por alguns dias tomando devidos cuidados até receber os resultados dos exames. Somente procurar orientação médica caso os sintomas aumentarem e desenvolver febres, tosses e dificuldade respiratória (FIOCRUZ, 2020).

Em casos de idosos, por exemplo, que necessitam de ajuda no dia a dia, a pessoa responsável pelo mesmo deve seguir as instruções corretas de proteção, inclusive o uso de máscaras descartáveis (FIOCRUZ, 2020). Tendo em vista o número crescente de casos de COVID-19, o Ministério da Saúde manifestou que o uso de máscaras, tanto as caseiras, de tecido, como as cirúrgicas, quando combinado com as demais práticas de higiene, pode ser um recurso importante para minimizar a disseminação de gotículas que possam conter o vírus. As pessoas que se submeterem a utilizar, devem seguir as práticas corretas de uso, desde a remoção ao descarte, assim como higienizar devidamente as mãos antes e após a remoção (BRASIL, 2020, p. 18).

Como medida preventiva alguns locais passaram a adotar o lockdown, o termo pode ser traduzido como confinamento e refere-se ao bloqueio total de uma região, imposta pelo Estado ou Justiça. É a medida adotada mais rígida durante situações extremas, como uma pandemia. O cidadão é restrito de circular em áreas públicas sem motivos emergenciais, cruzar fronteiras e muitas vezes pode ter um toque de recolher. A fiscalização é feita pelo próprio governo. Diante do avanço do novo coronavírus no Brasil, alguns estados e municípios avaliaram que as regras de distanciamento social não têm sido suficiente e aumentaram a restrição da circulação das pessoas decretando o lockdown. O Maranhão foi o primeiro estado a ter cidades com esta medida (TEIXEIRA, 2020). 
As regras do confinamento variam conforme o local adotado, mas os cidadãos só podem sair à rua por motivos de emergência. Geralmente ficam abertos farmácias, hospitais, supermercados e outros locais que prestem serviços essenciais. O trânsito da região pode ficar parcialmente ou totalmente suspenso. Aeroportos, rodoviárias, estações de trem também podem ser fechados e só é permitido a passagem por motivos de emergência ou a trabalho. O que o diferencia do isolamento social é que este é uma recomendação do governo, adotada ou não de forma voluntária pela população, já o lockdown é uma medida imposta pelo Estado onde a população não tem trânsito livre e só funcionam serviços básicos e essenciais como, por exemplo, saúde, coleta de lixo e segurança pública (TEIXEIRA, 2020).

Os países tomam muitas medidas devido à alta taxa de propagação do vírus entre as pessoas. As medidas mais conhecidas são as restrições a voos para determinados países, gradualmente ampliadas para suspender todos os voos e proibir a entrada de estrangeiros, o isolamento de 14 dias e o monitoramento de sintomas para os que vieram de países sob risco, período designado como quarentena. A quarentena é uma medida de saúde pública essencial para controlar surtos, tem sido usada há séculos para prevenir a introdução, transmissão e disseminação de doenças infecciosas em uma população, pode ser voluntária ou obrigatória, não existe uma diretriz universal sobre a decisão de quarentena durante uma pandemia. Cada país toma suas próprias decisões de quarentena, levando em consideração suas condições e dinâmica (ALTUNTAS; GOK, 2021).

Medidas preventivas podem ser eficazes na redução da transmissão de vírus no público em geral e em grupos de risco definidos (grupos de idosos, crianças e pessoas com comorbidades). No entanto, a Covid-19 pode se espalhar em um ritmo acelerado sem ter nenhuma medida eficaz de mitigação.

\section{CONSIDERAÇÕES FINAIS}

A pandemia COVID-19 é a principal crise de saúde global da contemporaneidade. Mas a pandemia é muito mais que uma crise de saúde, é também uma crise socioeconômica sem precedentes, com efeitos sociais, econômicos, políticos e ambientais com repercussões de difícil dimensionamento. A importância de seguir as medidas de prevenção, assim como estar atento aos sintomas e a todas as formas de transmissão é imprescindível, já que não se trata apenas de uma pessoa, e sim de infectar familiares, amigos, vizinhos, é uma doença que pôs em evidência a tão importante empatia, entre outras questões tão relevantes quanto.

Ainda há um longo caminho até que se tenha total controle da mesma, através de um tratamento efetivo ou até mesmo evitando a Covid-19 com a vacinação. 


\section{REFERÊNCIAS}

ADHIKARI, S. P. et al. Epidemiology, causes, clinical manifestation and diagnosis, prevention and control of coronavirus disease (COVID-19) during the early outbreak period: a scoping review. Infect Diseases Poverty, v.9, n.1, p.1-12, 2020.

ALTUNTAS, F.; GOK, M. S. The effect of COVID-19 pandemic on domestic tourism: A DEMATEL method analysis on quarantine decisions. Int J Hosp Manag. v.92, e102719. 2021 Disponível em: https://pubmed.ncbi.nlm.nih.gov/33519015/. Acesso em: 19 mai. 2020.

ASADI, S. et al. The coronavirus pandemic and aerosols: Does COVID-19 transmit via expiratory particles? Aerosol Sci. Technol., v.54, n.6, p.635-638, 2020.

BRASIL. Sobre a doença. 22 fev. 2020. Disponível em: <https://coronavirus.saude.gov.br/sobre-adoenca\#transmissao>. Acesso em: 21 mai. 2020.

CHAN, J. F. et al. Genomic characterization of the 2019 novel human-pathogenic coronavirus isolated from a patient with atypical pneumonia after visiting Wuhan. Emerging Microbes Infect. v.9, n.1, p.221-236, 2020.

CONTICINI, E. et al. Can atmospheric pollution be considered a co-factor in extremely high level of SARSCoV-2 lethality in Northern Italy? Environ Pollut. v. 261, e114465.2020. Disponível em: https://www.ncbi.nlm.nih.gov/pmc/articles/PMC7128509/

CUI, J.; LI, F.; SHI, Z. L. Origin and evolution of pathogenic coronaviruses. Nat Rev Microbiol. v.17, n.3, p.181-92, 2019.

DATTA, P. K. et al. SARS-CoV-2 pandemic and research gaps: Understanding SARS-CoV-2 interaction with the ACE2 receptor and implications for therapy. Theranostics. v.10, n.16, p.7448-7464, 2020. Disponível em: https://www.ncbi.nlm.nih.gov/pmc/articles/PMC7330865/

FARIA, N.; MORALES, I.; CANDIDO, D. Genomic characterization of an emergent SARS-CoV-2 lineage in Manaus: preliminary findings. 2021. Disponível em: https://bit.ly/3a4n22X. Acesso em: 19 mai. 2020.

FIOCRUZ. Isolamento domiciliar, instruções para pacientes e familiares. 13 mar. 2020. Disponível em: $<$ https://portal.fiocruz.br/sites/portal.fiocruz.br/files/imagensPortal/

isolamento_domiciliar_covid19_logo_sus.jpg>. Acesso em: 19 mai. 2020.

GIACOMELLI, A. et al. Self-reported Olfactory and Taste Disorders in Patients With Severe Acute Respiratory Coronavirus 2 Infection: A Cross-sectional Study. Clin. Infect. Dis., v.71, n.15, p.889-890, 2020.

GUAN, W. et al. Clinical Characteristics of Coronavirus Disease 2019 in China. N. Engl. J. Med., v.382, n.18, p.1708-1720, 2020.

KUMAR, S. et al. Current understanding of the influence of environmental factors on SARS-CoV-2 transmission, persistence, and infectivity. Environ Sci Pollut Res Int. 2021. Disponível em: https://pubmed.ncbi.nlm.nih.gov/33387315/. Acesso em: 19 mai. 2020. 
LING, Y. et al. Persistence and clearance of viral RNA in 2019 novel coronavirus disease rehabilitation patients. Chin. Med. J. v.140, e105790, 2020. Disponível em: www.elsevier.com/locate/envint. Acesso em: 19 mai. 2021.

OPAS/OMS (a). Rede Regional de Vigilância Genômica de COVID-19. 2021. Disponível em: https://bit.ly/3bu0qez. Acesso em: 19 mai. 2021.

OPAS/OMS (b). Actualización Epidemiológica Enfermedad por coronavirus (COVID-19) 25 de janero de 2021. Disponível em: https://www.paho.org/es/alertas-actualizaciones-epidemiologicas. Acesso em: 19 mai. 2021.

OPAS/OMS (c). Actualización Epidemiológica Enfermedad por coronavirus (COVID-19)18 de mayo de 2021. Disponível em: https://www.paho.org/es/alertas-actualizaciones-epidemiologicas. Acesso em: 19 mai. 2021.

RODRIGUEZ-MORALES, A. J. et al. History is repeating itself, a probable zoonotic spillover as a cause of an epidemic: the case of 2019 novel Coronavirus. Inf Med. v. 28, p.3-5, 2020.

SALIAN, V. S. et al. COVID-19 Transmission, Current Treatment, and Future Therapeutic Strategies. Mol Pharm. v.18, n.3, p.754-771, 2021.

SANTOS, Maria Tereza. Como se prevenir do coronavírus? Disponível em: <https://saude.abril.com.br/medicina/como-se-prevenir-coronavirus/>. Acesso em: 20 maio 2020.

SHE, J. et al. 2019 novel coronavirus of pneumonia in Wuhan, China: emerging attack and management strategies. Clin Transl Med. v.9, n.1, p.19-20. 2020.

SUNGNAK, W. et al. SARSCoV-2 Entry Genes Are Most Highly Expressed in Nasal Goblet and Ciliated Cells within Human Airways. Nat. Med. v.26, n.5, 681-687, 2020.

TEIXEIRA, Lucas Borges. Lockdown: como funciona, o que é, significado e locais onde vale a medida. Disponível em: <https://noticias.uol.com.br/faq/lockdown-como-funciona-o-que-e-significado-e-regrasem-sp-e-mais-cidades.htm>. Acesso em: 10 maio 2020.

WANG, L. F.; ANDERSON, D. E. Viruses in bats and potential spillover to animals and humans. Curr Opin Virol., v.34, p.79-89, 2019.

WHO/2019-nCoV/genomic_sequencing/2021.1. Disponível em: https://bit.ly/38ulAr0. Acesso em: 19 mai. 2021.

WONG, M. C. et al. Evidence of recombination in coronaviruses implicating pangolin origins of $\mathrm{nCoV}$ 2019. Microbiology, v.1, 2020.

WU, Y. et al. Prolonged presence of SARS-CoV-2 viral RNA in faecal samples. Lancet Gastroenterol. Hepatol. v.20, e30083, 2020. Disponível em:https://doi.org/10.1016/S 2468-1253(20)30083-2. Acesso em: 19 mai. 2021.

XU, Y. et al. Characteristics of pediatric SARS-CoV-2 infection and potential evidence for persistent fecal viral shedding. Nat. Med. 2020. Disponível em: https://doi.org/10.1038/ s41591-020-0817-4. Acesso em: 19 mai. 2021. 
YANG, S. et al. The size and concentration of droplets generated by coughing in human subjects. J. Aerosol Med., v.20, n.4, p.484-494, 2007. 